\title{
Alcohol Synthesis from Synthesis Gas over Promoted Rhodium Catalysts: A Study of Promoter and Supports Effects
}

\author{
Zhao Guo ${ }^{1}$, Jingjing $\mathrm{Liu}^{2}$, Runzhe Tao ${ }^{1}$, Randall J. Meyer ${ }^{2}$, Robert Klie ${ }^{1}$ \\ ${ }^{1}$ Dept. of Physics, University of Illinois Chicago, 845 W Taylor St. Chicago, IL, USA \\ ${ }^{2}$.Dept. of Chemical Engineering, University of Illinois Chicago, 810 S. Clinton St, Chicgo, IL, USA
}

One of the largest societal challenges of our day is the quest for alternative fuel resources that will reduce our current greenhouse-gas emission. Using supported rhodium-based nano-catalysts to produce alcohols from syngas provides an alternative, and potentially cleaner, more efficient route to these conventional methods. It is reported that promotion with early transition metal elements can effectively increase alcohol selectivity. [1,2] In order to increase the promoter-metal interaction to maximize their effectiveness, the Strong Electrostatic Adsorption (SEA) and Dry Impregnation are used to steer the promoter precursor onto $\mathrm{Rh}$ oxide supported on $\mathrm{SiO}_{2}$. In a separate experiment, Mn-promoted $\mathrm{Rh}$ particles are supported on Cabon nano-tubes (CNTs) by the DI method. The catalysts were characterized by Scanning Transmission Electron Microscopy (STEM) and extended X-ray Adsorption Fine Structure (EXAFS) was used to characterize the chemical composition.

STEM imaging and EELS mapping work were performed on a JEOL-ARM 200CF aberration corrected microscope (70 pm spatial resolution and $350 \mathrm{meV}$ energy resolution) at UIC. Transmission X-ray Absorption Spectroscopy (XAS) of the Rh $K$-edge of the in-situ reduced $\mathrm{Rh} / \mathrm{SiO}_{2}$ series catalysts were measured at Argonne national Laboratory's Advanced Photon Source (APS) sector 10-BM. Alcohol synthesis reactions were investigated under isothermal plug flow conditions at $20 \mathrm{bar}, 285^{\circ} \mathrm{C}$, and a $2: 1$ $\mathrm{H}_{2}$ : $\mathrm{CO}$ ratio in order to compare the catalytic performance of different catalysts at different $\mathrm{CO}$ conversion.

As seen in Fig.1a, EELS mapping shows that for DI samples, the promoter is not strongly associated with the metallic Rh particle, while from Fig. 1b, we can clearly see that the SEA promoted catalyst shows intimate promoter-active metal interactions. The dark field STEM imaging of Mn promoted Rh catalysts over $\mathrm{SiO}_{2}$ is shown below in Fig. 2. The $\mathrm{Rh}$ particles exhibited small particle sizes (high dispersion) and the average particle size of the catalyst promoted by SEA is $2.8 \pm 0.5 \mathrm{~nm}$. In addition to STEM imaging, EXAFS is also used to verify the average particle size. Their comparison is listed in Table 1. It is obvious that the particle sizes acquired by these two different techniques are in close agreement. XANES measurements after in-situ reduction at $210^{\circ} \mathrm{C}$ show spectra characteristic of metallic $\mathrm{Rh}$ for all the catalysts, $\mathrm{Rh}$ foil and rhodium oxide were used as standard references (Fig. 3). Therefore, we can conclude that no matter how we add the promoters to the Rh catalysts, the Rh oxide present in the unreduced catalyst is reduced into metallic $\mathrm{Rh}$ after reduction treatment. In the future work, we are going to test the catalytic performance of the $\mathrm{Mn}$ promoted $\mathrm{Rh}$ on $\mathrm{SiO}_{2}$ catalysts for $\mathrm{CO}$ hydrogenation reaction, as well as study the reactivity behavior of $\mathrm{Mn}$ promoted $\mathrm{Rh}$ catalysts supported on carbon nanotubes, and further characterization by STEM/EELS and XAS will be done to identify the Mn promoter phases (oxidation state).

References:

[1] Subramani, V., and Gangwal, S.K., Energy \& Fuels, 22, 814 (2008). 
[2] Spivey, J.J., and Egbebi, A., Chemical Society Reviews, 36, 1514 (2007).

[3] Regalbuto, J.R., in "Catalyst Preparation: Science and Engineering” (Taylor \& Francis/ CRC Press) P.297. Boca Raton, 2006.

[4] This research is supported by a grant from the National Science Foundation (CBET-1067020)

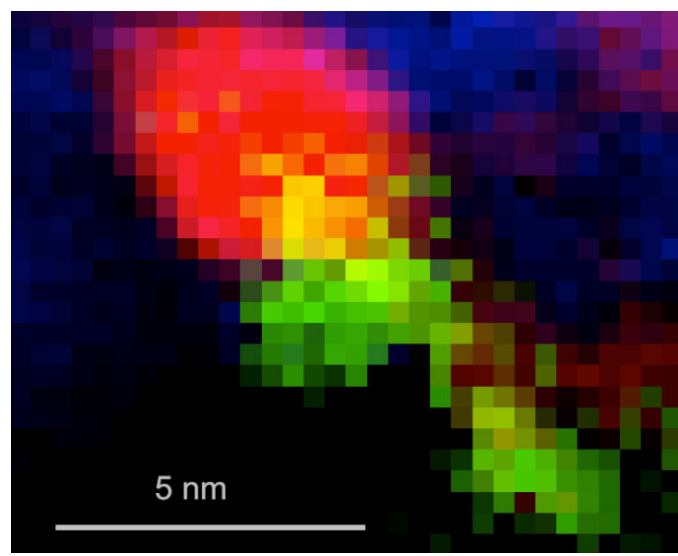

(a)

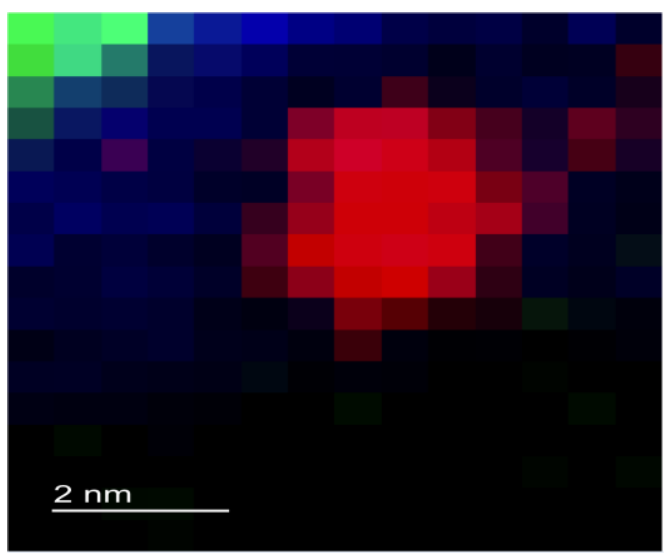

(b)

Figure 1. EELS mapping of $\mathrm{Mn} / \mathrm{Rh} / \mathrm{SiO}_{2}$ created by (a) $\mathrm{DI}$ (b) $\mathrm{SEA}$

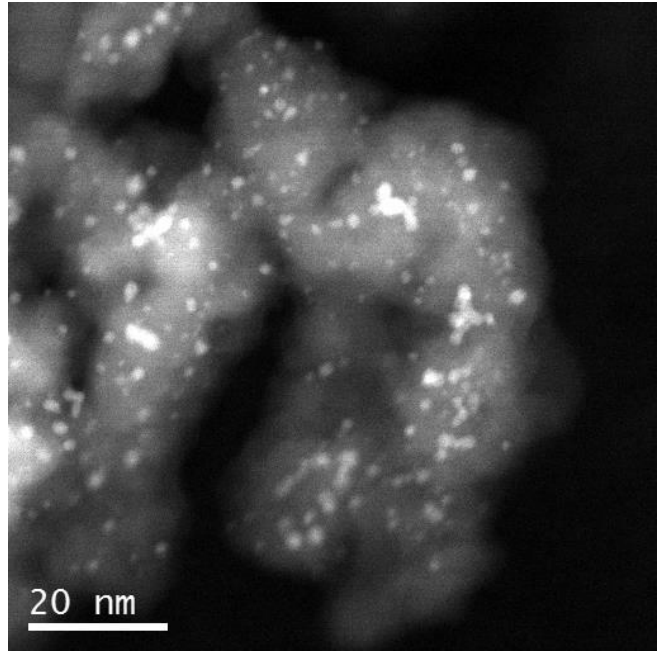

Figure 2. STEM imaging of $1 \% \mathrm{Mn} \_\mathrm{SEA} \_4 \% \mathrm{Rh} / \mathrm{SiO}_{2}$

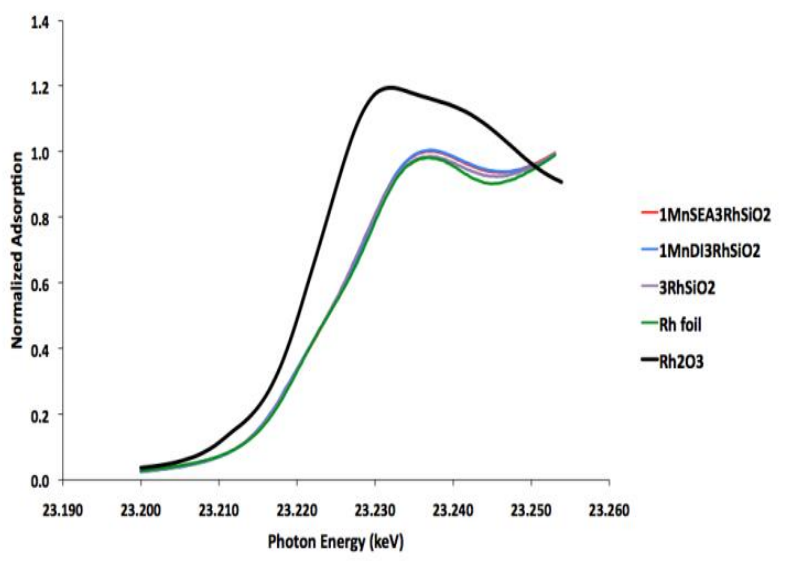

Figure 3. XANES spectrum of Rh K edge of $1 \mathrm{wt} \% \mathrm{Mn}$ promoted $3 \mathrm{wt} \% \mathrm{Rh} / \mathrm{SiO} 2$ catalysts plotted with appropriate standards

\begin{tabular}{|c|c|c|c|c|c|}
\hline Catalysts & $\begin{array}{c}\text { Coordination } \\
\text { Numbers }\end{array}$ & $\begin{array}{c}\text { Bonding } \\
\text { Distance }\end{array}$ & $\begin{array}{c}\text { Degree of } \\
\text { Disorder }\end{array}$ & $\begin{array}{c}\text { Particle } \\
\text { size by } \\
\text { EXAFS }\end{array}$ & $\begin{array}{c}\text { Particle } \\
\text { size by } \\
\text { STEM }\end{array}$ \\
\hline $1 \% \mathrm{Mn}(\mathrm{SEA}) 3 \% \mathrm{Rh} / \mathrm{SiO} 2$ & 7.6 & 2.68 & $0.001 \AA$ & $2.8 \mathrm{~nm} \pm 0.3$ & $2.8 \mathrm{~nm} \pm 0.5$ \\
\hline
\end{tabular}

Table 1. Particle size distribution of catalysts obtained by EXAFS and STEM 